\title{
GEORREFERENCIAMENTO DE UMA ÁREA DE EXTRAÇÃO DE AREIA EM MORRO BRANCO, MUNICÍPIO DE FERREIRA GOMES, ESTADO DO AMAPÁ
}

\section{ARTIGO ORIGINAL}

SANTOS, Ana Beatriz Oliveira ${ }^{1}$

FEIO, Stefanie Cecília Passinho ${ }^{2}$

DIAS, Claudio Alberto Gellis de Mattos ${ }^{3}$

FECURY, Amanda Alves ${ }^{4}$

OLIVEIRA, Euzébio de ${ }^{5}$

DENDASCK, Carla Viana ${ }^{6}$

${ }^{1}$ Estudante do Curso Integrado em Mineração, Campus Macapá, Instituto de Ensino Básico, Técnico e Tecnológico do Amapá (IFAP).

${ }^{2}$ Estudante do Curso Integrado em Mineração, Campus Macapá, Instituto de Ensino Básico, Técnico e Tecnológico do Amapá (IFAP).

${ }^{3}$ Biólogo, Doutor em Teoria e Pesquisa do Comportamento, Professor e pesquisador do Programa de Pós-Graduação Profissional em Educação Profissional em Rede Nacional (ProfEPT) do Instituto de Ensino Básico, Técnico e tecnológico do Amapá (IFAP).

${ }^{4}$ Biomédica, Doutora em Doenças Topicais, Professora e pesquisadora do Curso de Medicina do Campus Macapá, Universidade Federal do Amapá (UNIFAP).

${ }^{5}$ Biólogo, Doutor em Doenças Topicais, Professor e pesquisador do Curso de Educação Física da, Universidade Federal do Pará (UFPA).

6 Teóloga, Doutora em Psicanálise, pesquisadora do Centro de Pesquisa e Estudos Avançados- CEPA. 
SOUZA, Sandro Rogerio Balieiro de ${ }^{7}$

SANTOS, Ana Beatriz Oliveira. Et al. Georreferenciamento de uma área de extração de areia em Morro Branco, Município de Ferreira Gomes, Estado do Amapá. Revista Científica Multidisciplinar Núcleo do Conhecimento. Ano 04, Ed. 12, Vol. 01, pp. 41-54. Dezembro de 2019. ISSN: 2448-0959, Link de acesso: https://www.nucleodoconhecimento.com.br/geografia/georreferenciamentode-uma-area

\section{RESUMO}

A humanidade sempre teve 0 instinto de saber a sua posição em relação ao espaço em que vive. A bússola foi a grande revolucionária dentre as técnicas de posicionamento, criada pelos chineses, e mudou todo o cenário das navegações, mas ainda assim não era completamente eficiente. A partir dos avanços da eletrônica surgiram novas tecnologias baseados na rádio navegação, que utilizava as ondas de rádio e seus impulsos. A corrida espacial e os satélites artificiais possibilitaram a visualização da Terra a partir do espaço. A partir de 1980 o Sistema de Posicionamento Global (GPS) passou a ser um sistema aberto para todos. O objetivo deste trabalho foi mostrar as técnicas de georreferenciamento e os conhecimentos de geomática aplicados, como importante ferramenta, a exploração geológica de uma área. A área-alvo do estudo foi a localidade denominada areal Morro Branco, localizada no município de Ferreira Gomes, estado do Amapá, Brasil. Foram marcados nove pontos em locais distintos da BR-156 e diversos outros pontos foram coletados por outros alunos já na localidade. No areal foram marcados vários pontos a fim de demarcar a área de exploração da areia no local. Constatamos a consolidação do aprendizado teórico e prático através da correlação existente entre os conteúdos estudados durante o curso de técnico em mineração, evidenciando-se os componentes curriculares: geologia geral, topografia e meio ambiente e segurança no

${ }^{7}$ Geólogo. Mestre em Geologia e Geoquímica. Professor e pesquisador do curso de Mineração do Instituto de Ensino Básico, Técnico e tecnológico do Amapá (IFAP). 
trabalho. Consolidou-se as informações de campo na forma de mapas de detalhe da área do areal Morro Branco, bem como as interpretações quanto a localização geográfica, com precisão, da jazida de areia.

Palavras-chave: Georreferenciamento, GPS, areal.

\section{INTRODUÇÃO}

A humanidade sempre teve 0 instinto saber a sua posição em relação ao espaço em que vive. A época das grandes navegações foi um marco que representou um grande avanço na tecnologia de posicionamento, a necessidade de ir e voltar pelo mesmo caminho, além do fato da descoberta de novas terras fez com que surgissem novas técnicas. Por muito tempo o sol e os astros foram utilizados como guia, porém as variantes climáticas influenciavam diretamente na eficiência do método, muitas vezes levando a falha. A bússola foi a grande revolucionária dentre as técnicas de posicionamento, criada pelos chineses, e mudou todo o cenário das navegações, mas ainda assim não era completamente eficiente, já que apenas fornecia a medição da latitude, com uma grande margem de erro, apesar de vários estudos em torno da bússola, a navegação por celestes não apresentava precisão. (MONICO, 2000).

Segundo Monico (2000), a partir dos avanços da eletrônica surgiram novas tecnologias baseados na rádio navegação, que utilizava as ondas de rádio e seus impulsos, como o sistema LORAN (Long Range Navigation) e ÔMEGA, entretanto a limitação desses sistemas, o alto custo e a falta de precisão ainda eram problemas presentes. Esses só foram solucionados na década de 1970 com a criação do GPS (Global Positioning System) ou Sistema de Posicionamento Global, o marco inicial foi realizado pela antiga união soviética com o lançamento em órbita do primeiro satélite artificial, intitulado Sputnik, porém foram os Estados Unidos, com seu departamento de defesa, que levou em frente o projeto e o intitulou de NAVSTAR (Navigation Satellite Time and Ranging), para fins de uso unicamente militares. A partir de 1980, com decisão do então Presidente Norte Americano Ronald Reagan, o GPS passou a ser um sistema aberto para todos, restringindo o de maior precisão ao serviço militar, 
em seguida em 1995 o mesmo chegou a sua versão final e foi totalmente integrado a novas técnicas de mapeamento terrestre (SANTOS, 2012).

O GPS possui um funcionamento constante, ou seja, $24 \mathrm{~h}$ por dia, sendo capaz de fornecer coordenadas bidimensionais e tridimensionais a qualquer momento, as mesmas são obtidas a partir da medida das distâncias entre o receptor e o satélite (CARVALHO e ARAÚJO, 2009a).

Foi a partir dos avanços dessas tecnologias que surgiu o georreferenciamento, 0 termo é um neologismo, visto que não é originário da língua portuguesa, foi criado a partir da necessidade de intitular a técnica de posicionamento relacionado a Geodésia e a cartografia. Essa técnica consiste na determinação de um ponto na superfície do planeta por meio de coordenadas que são transformadas em dados a partir do sistema de referência adotado por cada região (ROQUE et al., 2006).

Ao georreferenciar uma imagem ou mapa as suas coordenadas se tornam conhecidas em um sistema, isso ocorre por meio dos pontos de controle, que são locais utilizados como referência. Os mesmos precisam ser nítidos e de fácil identificação, como estradas, edifícios e montanhas, a coleta dos pontos de controle pode ocorrer por meio de levantamentos topográficos. Com isso qualquer ponto na superfície do planeta pode ser calculado e registrado. Esses cálculos são feitos por meio do conceito de Geodésia, utilizando os mesmos para medir os pontos na superfície física e depois passa-los para a superfície matemática, que considera todas as variáveis de curvatura e relevo (MENZORI, 2017).

Portanto o georreferenciamento se mostra uma ferramenta muito útil e eficaz para o controle de registro de imóveis e nas fiscalizações ambientais. No Brasil a prática ganhou destaque em 2001 a partir da aprovação da Lei Federal 10.266 onde diz que todos os imóveis rurais estejam registrados ao Sistema Geodésico Brasileiro (ROQUE et al., 2006). 


\section{LOCALIZAÇÃO}

O município de Ferreira Gomes (Figura 1) foi criado em 17 de dezembro de 1987 (Lei 7.639/87). Dentre os fatores históricos de seu desenvolvimento até sua emancipação político-administrativa, destaca-se a condição estratégica que desempenhou como entreposto rodoviário no antigo traçado da BR-156. Hoje o município é o décimo segundo maior do estado em número de habitantes, ficando atrás do município de Macapá e de outros dez municípios (AMAPÁ, 2017).

Sua economia está baseada no desenvolvimento de atividades agropecuárias tradicionais e, mais recentemente, no investimento ao turismo para o qual vem colocando em prática a realização de eventos e a instalação de infraestrutura destinada ao aproveitamento das ambientações paisagísticas e de lazer do município. Possui atualmente uma população estimada de 7.591 pessoas (IBGE, 2017).

A cidade de Ferreira Gomes localiza-se no estado do Amapá nas coordenadas geográficas: lat. $00^{\circ} 51^{\prime} 17$ “N e long. 51010'25” W (FERREIRA e SANTOS, 2017). Faz Fronteira com os municípios de Pracuúba e Tartarugalzinho a norte, Cutias a leste, Macapá a sudeste, Porto Grande a sudoeste e Serra do Navio a noroeste (Figura 1).

Figura 1. Mapa do município de Ferreira Gomes no estado do Amapá.



(Adaptado de IBGE, 2019).

$\mathrm{RC}: 42128$

Disponível em: https://www.nucleodoconhecimento.com.br/geografia/georreferenciamento-deuma-area 


\section{CONTEXTO GEOLÓGICO}

O Ministério de Minas e Energia (MME) caracteriza a geologia do Estado do Amapá em quatro unidades geotectônicas diferentes entre si, sendo elas: núcleos preservados do pré-cambriano, cinturão de cisalhamento pré-cambriano, sedimentos monoclinais paleozóicos e sedimentos tabulares meso-cenozóicos (Figura 2) (OLIVEIRA et al., 2010). O Instituto de Pesquisas Científicas e Tecnológicas do Estado do Amapá criou um arcabouço geológico simplificado do Estado do Amapá, onde o estado é caracterizado por duas unidades geotectônicas distintas: crosta antiga, retrabalhada ou não; e coberturas plataformais (RABELO et al., 2008).

Figura 2 Arcabouço geotectônico e distritos metalogenéticos do Amapá: 1 - Lourenço (Au), 2 -Tartarugalzinho (Au), 3 - Serra do Navio (Mn), 4 - Serra do Navio/Vila Nova (Au), 5 - Bacuri (Cr), 6 -Igarapé do Breu (Cr) e, 7 - Cupixi (Au).

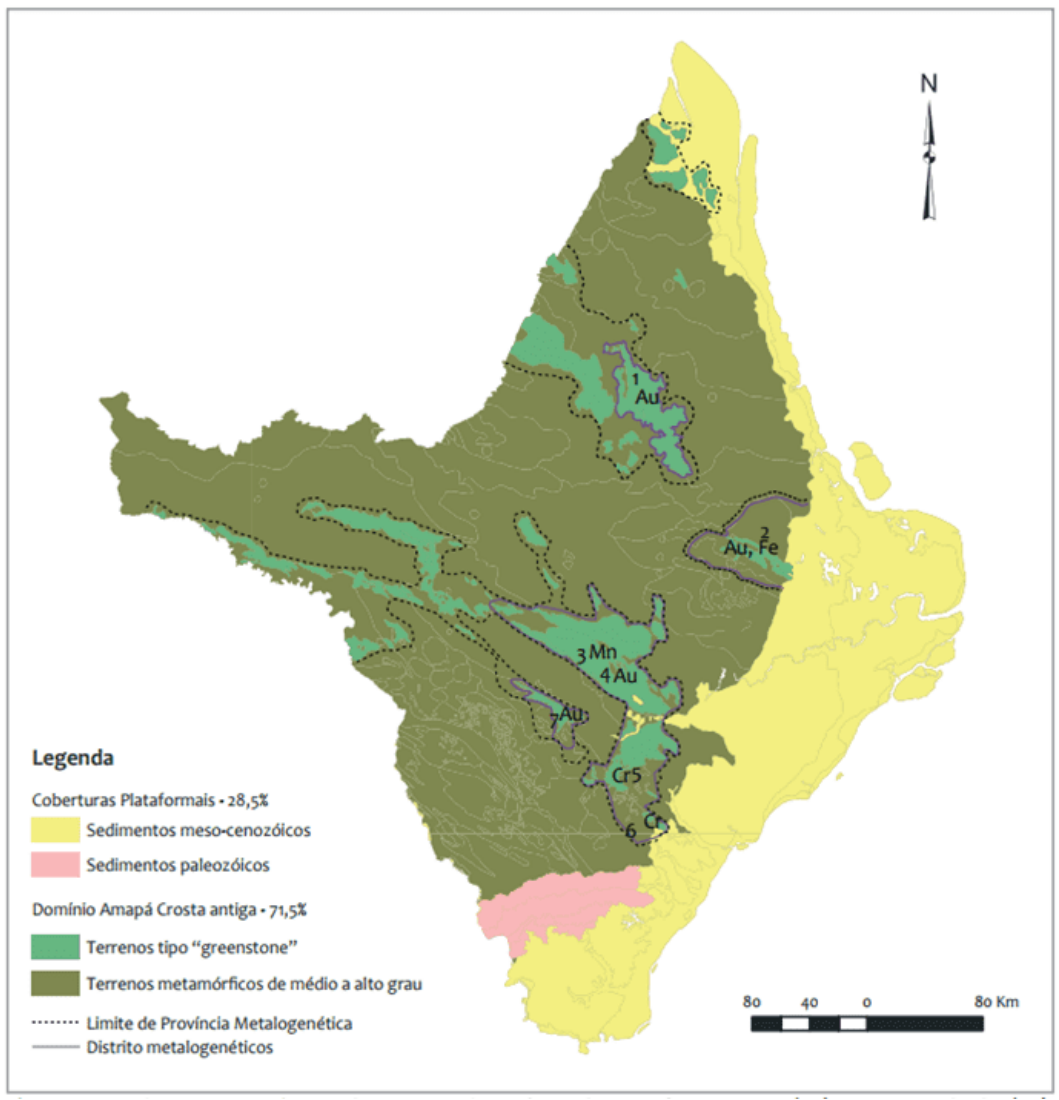

(RABELO et al., 2008).

$\mathrm{RC}: 42128$

Disponível em: https://www.nucleodoconhecimento.com.br/geografia/georreferenciamento-deuma-area 
A crosta antiga corresponde ao domínio Amapá da Província Transamazônica e ocorre em $71,5 \%$ do estado, nas suas porções norte, oeste e central. O embasamento antigo (arqueano a paleoproterozóico) seria composto por terrenos metamórficos de médio a alto grau, formados por gnaisses, granuloso e magmáticos pertencentes às unidades estratigráficas Guianense (Complexo), Tumucumaque (Complexo) e Tartarugal Grande. Este domínio é intrudido por corpos ou suítes plutônicos paleoproterozóicos como o enderbito Cobra e por rochas máficas-ultramáficas do Complexo Bacuri, as quais foram metamorfizadas em fácies anfibolito, tendo por principais litotipos: anfibolitos, serpentinitos, tremolitos e cromititos (PIMENTEL et al., 2002; MAGALHÃES et al., 2007).

De acordo com o MME ocorrem ainda rochas supracrustais paleoproterozóicas, caracterizadas por sequências metavulcano-sedimentares de fácies xisto verde a anfibolito, tipo "greenstone belt", orientadas sob o "trend" NW-SE. Pertencem aos Grupos Vila Nova e Serra Lombarda, sendo representadas por litotipos diversos: xistos, quartzitos, anfibolitos, metacherts, metabifs, metaconglomerados, metavulcânicos e outros. Também são cortadas por diversas manifestações ígneas intrusivas proterozóicas posteriores, como o Granodiorito Falsino e Alcalinas Mapari (OLIVEIRA et al., 2010).

Por efeito da abertura do oceano Atlântico durante o permiano-triássico, o domínio Amapá da Província Transamazonas foi cortado por um enxame de diques de diabásio, denominados de Suíte Intrusiva Cassiporé (MAGALHÃES et al., 2007).

O segundo domínio geotectônico corresponde às coberturas plataformais paleomesozóicas da bacia do Amazonas e as sequências sedimentares cenozóicas. Parte da porção sul do estado corresponde ao flanco norte da Bacia do Amazonas onde ocorrem sedimentos clásticos a pelíticos, pertencentes às seguintes unidades (CPRM, 2017; IBGE, 2019):

-Formação Trombetas de idade siluriana e representada principalmente por arenitos finos; 
-Formação Maecuru, datada do devoniano, onde predominam também fácies arenosas;

-Formação Erere, caracterizada por camadas de siltitos devonianos;

-Formação Curuá, composta por folhelhos pretos marinhos e piritosos também devonianos.

Ainda na porção sul ocorrem sedimentos mesozóicos (cretáceo) da Formação Alter do Chão representados por rochas clásticas de origem continental: arenitos, siltitos e argilitos caulínicos. Já a porção litorânea (leste) e sul do estado, correspondem à planície flúvio-costeira e estuarina que é subdividida em: zona atlântica (predominam os processos marinhos com contribuição sedimentar do rio Amazonas) e zona estuarina (dominada por processos mistos) (OLIVEIRA et al., 2010).

Ambas as segmentações registram sedimentação de idade terciária, representada pelo Grupo Barreiras (argilitos, siltitos e arenitos) e depósitos sedimentares pelíticos a psamíticos recentes, ao longo de canais, planícies de inundação, mangues e cordões litorâneos. São reconhecidos ainda litotipos de alteração supergênica, desenvolvidos durante o terciário sobre rochas mais antigas (OLIVEIRA et al., 2010).

No Amapá existe o pólo principal de produção de areia, cascalho e brita se localiza nos municípios de Porto Grande e Ferreira Gomes, que abastecem os dois maiores centros urbanos do estado: Macapá e Santana. São diversos empreendimentos mineiros de pequeno porte dedicados à extração de areia, seixo ou cascalho e, mais recentemente, à produção de brita. Até agosto de 2009 estavam registrados nos dois municípios cerca de 39 processos de requerimento mineral para agregados de construção, sendo: dezoito para areia, doze para seixo e nove para brita (OLIVEIRA et al., 2010).

O areal Morro Branco (Figura 3) está localizado na porção centro-sul do Estado do Amapá, nos municípios de Porto Grande e Ferreira Gomes, sendo o principal polo 
fornecedor de agregados de construção (areia, seixo e brita) que abastecem as obras civis e de pavimentação no estado (MAGALHÃES et al., 2007).

Figura 3. Visões do areal Morro Branco, município de Ferreira Gomes, AP.

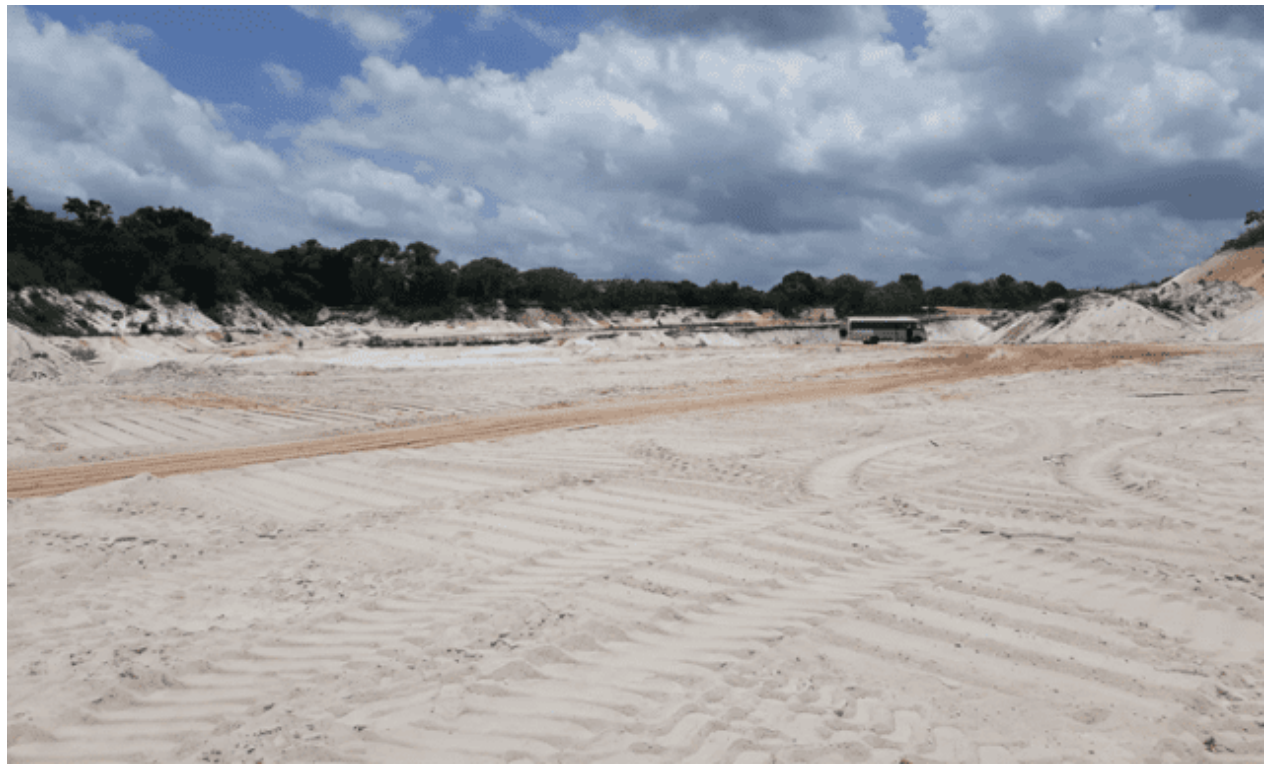

(Fonte: Autor).

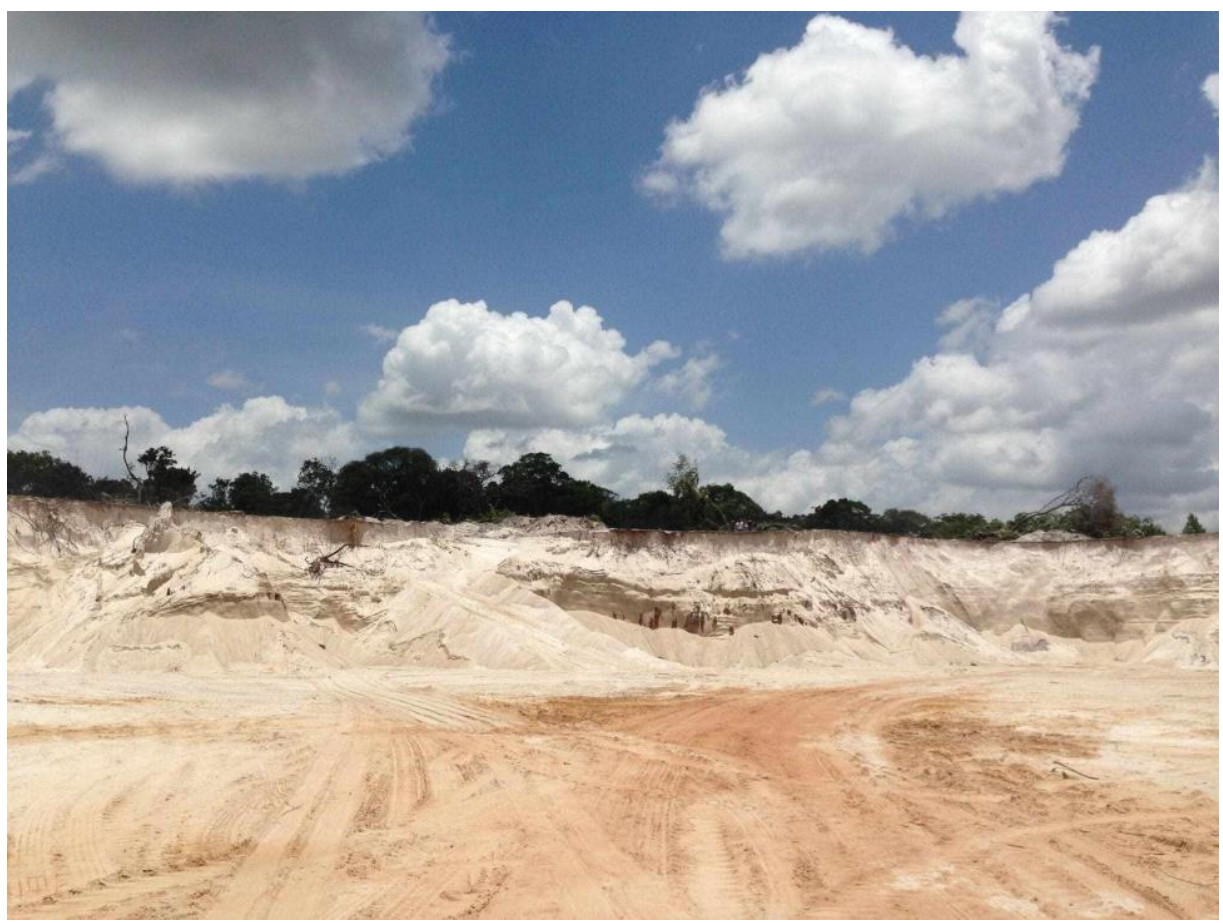

(Fonte: Autor).

$\mathrm{RC}: 42128$

Disponível em: https://www.nucleodoconhecimento.com.br/geografia/georreferenciamento-de$\underline{\text { uma-area }}$ 
Os depósitos estão localizados no entorno da sede do município de Ferreira Gomes. São constituídos por areia de granulação média, quartzosas com camadas de espessura média de 8 a 10 metros (Figura 4), por vezes intercalados com lentes de areia fina ou material pelítico. A geometria, dimensões, cubagem e a origem destes depósitos ainda não são bem conhecidas. Ocorrem próximos do contato da planície flúvio-costeira amapaense com rochas intemperizadas do embasamento cristalino (OLIVEIRA et al., 2010).

Figura 4. Depósito de areia, Areal Morro Branco.

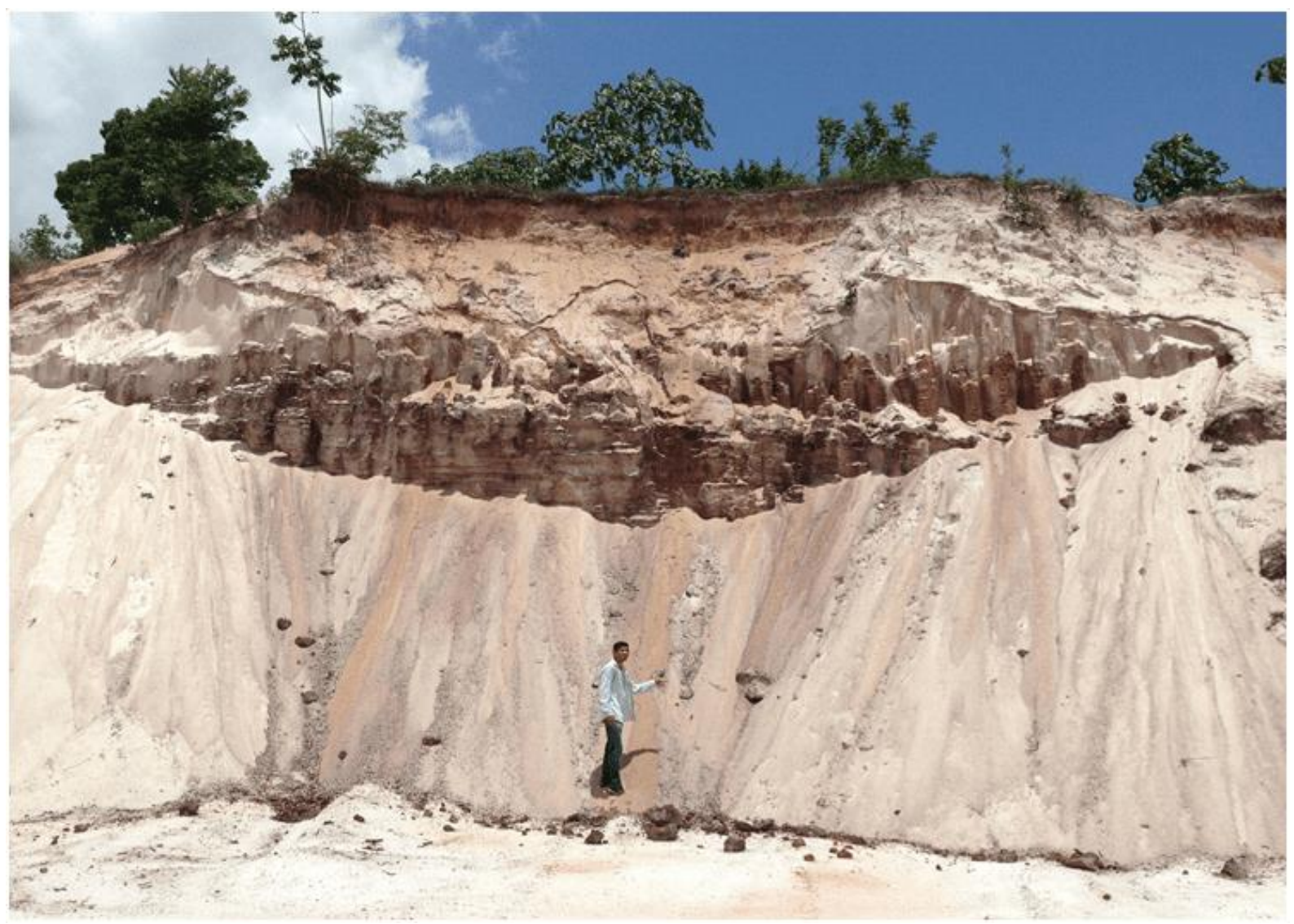

(Fonte: Ana Karoline Bezerra)

\section{GEORREFERENCIAMENTO}

Os meridianos e os paralelos são linhas imaginárias e se encontram na categoria de coordenadas geodésicas. Os paralelos são círculos que se encontram em paralelo a

Disponível em: https://www.nucleodoconhecimento.com.br/geografia/georreferenciamento-de- 
linha do equador. Sobre um determinado paralelo, a latitude é constante. Sobre o Equador, a latitude é igual a zero, medindo-se de $0^{\circ}$ a $90^{\circ}$, para norte (positiva) e para sul (negativa). Os paralelos se encontram na orientação Leste-Oeste (GOMES, 2010).

Os meridianos são linhas imaginárias que passam através dos polos e ao redor da terra na orientação norte-sul e são medidos de $0^{\circ}$ a $180^{\circ}$ na orientação leste (positivo) e oeste (negativo), sendo o ponto de partida para numeração dos meridianos o meridiano que passa pelo Observatório de Greenwich, na Inglaterra. Logo, o meridiano de Greenwich é o Meridiano Principal (GOMES, 2010).

O conjunto dos meridianos e paralelos forma uma rede de linhas imaginárias ao redor do globo, constituindo as coordenadas geográficas. As coordenadas são medidas através de um sistema conhecido por Longitude e Latitude (GOMES, 2010; SANTOS, 2012).

Cada ponto marcado na superfície terrestre forma um ponto de interseção entre um meridiano e um paralelo e esse ponto pode ser identificado através da identificação da latitude e da longitude em que ele se encontra. Latitude é a distância em graus, minutos e segundos, ao Norte ou Sul, em relação à linha do Equador, e vai de 0 a $90^{\circ}$. Assim, a latitude é o ângulo formado entre a linha do Equador e o paralelo em que o ponto está localizado. Longitude é a distância em graus, minutos e segundos, a Leste ou Oeste, em relação ao Meridiano de Greenwich, e vai de 0 a 180․․ Assim, a longitude é o ângulo formado entre o Meridiano Principal (Greenwich) e o meridiano em que o ponto está localizado, em relação ao centro da Terra (GOMES, 2010; SANTOS, 2012).

A projeção Universal Transversa de Mercator (UTM) é um tipo de projeção favorável a representar áreas que são maiores em extensão Norte-Sul. É o tipo de projeção mais utilizado no Brasil para a representação de mapas. O sistema utiliza como superfície de projeção 60 cilindros transversais à superfície de referência. Cada cilindro é responsável pela representação de 6 o de longitude, contada a partir do antemeridiano de Greenwich e cada cilindro está compreendido entre $80^{\circ} \mathrm{S}$ e $84^{\circ} \mathrm{N}$. As coordenadas no Sistema UTM são representadas pelas letras N (Latitude) e E 
(Longitude), expressas em metros e sempre com valores positivos. Alguns valores de UTM são válidos tanto para Norte quanto ao Sul do Equador, assim, é importante especificar o hemisfério (N ou S) (GOMES, 2010).

O sistema GPS, Global Positioning System (Sistema de Posicionamento Global) é um sistema baseado em sinais de satélite. É composto por uma rede de 24 satélites sob domínio do departamento Norte-Americano de Defesa. Esse sistema foi desenvolvido para operar em quaisquer condições climáticas e em qualquer parte do planeta, a qualquer momento e sem fins lucrativos (GOMES, 2010). Era inicialmente utilizado exclusivamente para fins militares e, com o passar do tempo, essa tecnologia começou a ser utilizada pelo público em geral e a ter diversos avanços tanto em sua técnica quanto na popularidade do sistema. Trata-se de um sistema, composto por satélites e dispositivos receptores, que recolhe informação acerca do posicionamento e do tempo, o que permite uma navegação precisa e contínua em todo o planeta, em tempo real (PIRES et al., 2014).

O funcionamento desta ferramenta consiste basicamente na medida das distâncias entre o usuário e mais quatro satélites; através da identificação das coordenadas desses satélites é possível saber a localização do usuário quando está no mesmo sistema de referência dos satélites (MONICO, 2000) Em outras palavras, o GPS baseia-se na determinação da distância entre um ponto, o receptor, e outros de referência, os satélites. Sabendo a distância que nos separa de 3 pontos podemos determinar a nossa posição relativa a esses mesmos 3 pontos, sendo necessário, para uma maior precisão, quatro satélites (GOMES, 2010).

Os receptores GPS coletam dados enviados pelos satélites, transformando-os em coordenadas, distâncias, tempo, deslocamento e velocidade, através de processamento em tempo real ou a posteriori. Atualmente, há uma grande quantidade de receptores no mercado civil, para as mais diversas aplicações, com destaque para a Cartografia e Geodésia. Além de receber e decodificar os sinais dos satélites, os receptores são verdadeiros computadores que permitem várias opções: referências; 
sistemas de medidas; sistemas de coordenadas; armazenamento de dados; troca de dados com outro receptor ou com um computador (CARVALHO e ARAÚJO, 2009a).

O sistema dos receptores trabalha com a triangulação dos satélites, cujos os sinais são recebidos por eles. Cada satélite emite um sinal codificado que o identifica. $O$ aparelho receptor interpreta o sinal enviado e calcula a distância dele até o satélite que emitiu o sinal. Esse cálculo é efetuado em função do tempo que o sinal demora até chegar ao receptor, sabendo-se que o sinal viaja à velocidade da luz. Quando utilizado para identificação de pontos ou posicionamento, esse sistema utiliza as coordenadas dos satélites. O GPS utiliza um sistema de referência tridimensional para a determinação da posição de um ponto da superfície da Terra ou próximo a ela. As coordenadas dessas posições são adquiridas no sistema geodésico WGS-84, ao qual o GPS encontra-se referido (CARVALHO e ARAÚJO, 2009a).

\section{OBJETIVO}

Mostrar as técnicas de georreferenciamento e os conhecimentos de geomática, aplicados a exploração geológica de uma área de extração de areia, que se encontra na localidade denominada areal Morro Branco, no município de Ferreira Gomes, estado do Amapá, Brasil.

\section{MÉTODO}

Os pontos são posições ou marcas terrestres que são registradas e/ou guardadas no receptor GPS. Esses pontos possuem coordenadas específicas e através da marcação destes podemos traçar trajetos e/ou medir distâncias (GOMES, 2010). O receptor GPS utilizado na marcação de pontos foi o da marca GARMIN no modelo eTrex 30. A marcação de pontos se deu através do esquema apresentado abaixo (Figura 5). 
Figura 5. Aparelho receptor de sinal GPS e o esquema da marcação de pontos.
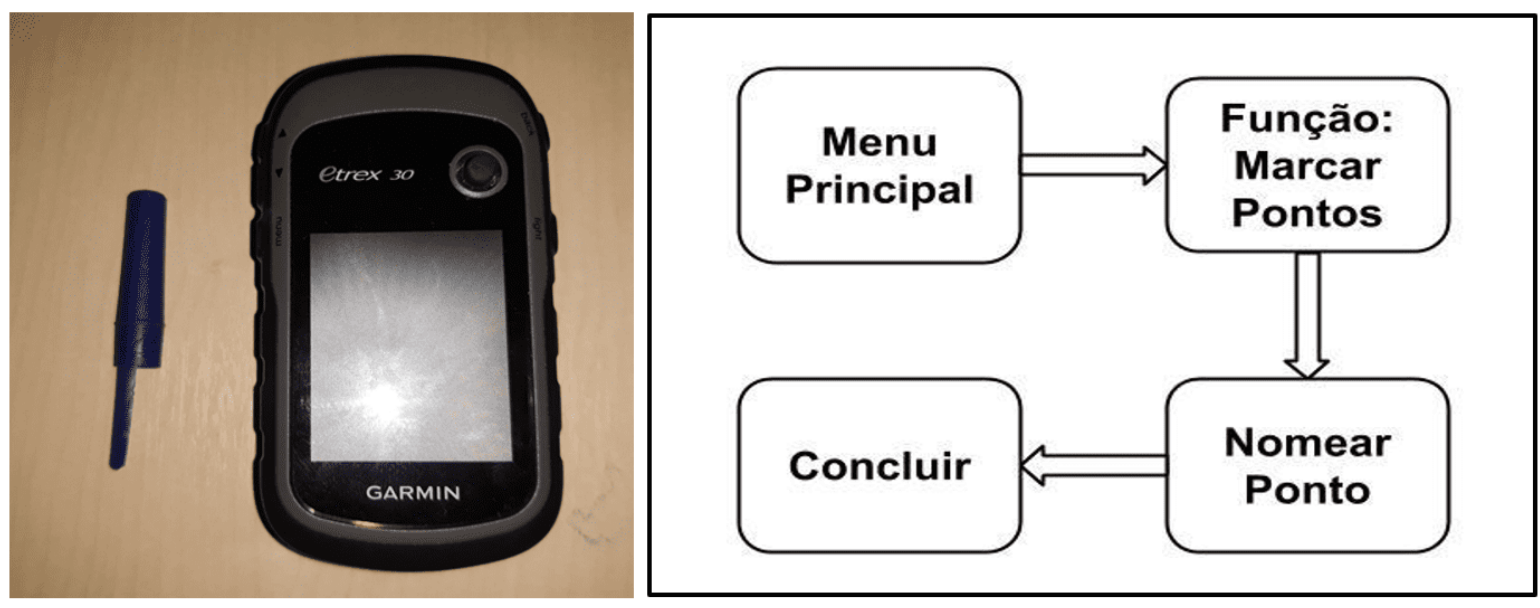

(Fonte: Autor)

A primeira marcação de ponto $(\mathrm{P} 1)$ se deu logo ao início do trajeto em frente ao Instituto Federal do Amapá (IFAP). Seguiu-se o percurso pela BR 156 onde no KM 9, em frente a polícia rodoviária federal, foi marcado o segundo ponto (P2). Em seguida foram marcados pontos no KM 21 e KM 50, respectivamente P3 e P4. Antes de chegar ao destino final, adentrou-se o município de Porto Grande onde foram marcados mais dois pontos, P5 na entrada do município e P6 em frente ao balneário da cidade. Posteriormente voltou-se a estrada em direção ao areal, ao chegar ao ramal que levava ao destino marcou-se dois pontos, P7 e P8, por fim chega-se ao destino finalizando o trajeto pela marcação do P9, já no município de Ferreira Gomes onde se localiza o Areal Morro Branco (Tabela 1 e Figura 6, 7).

Tabela 1. Descrição do trajeto, latitude, longitude e descrição dos pontos.

\begin{tabular}{|l|l|l|l|}
\hline Pontos & Latitude & Longitude & Descrição \\
\hline P1 & $9716.16 \mathrm{~m} \mathrm{~N}$ & $489802.99 \mathrm{~m} \mathrm{E}$ & Frente do IFAP \\
\hline P2 & $11332.67 \mathrm{~m} \mathrm{~N}$ & $486472.09 \mathrm{~m} \mathrm{E}$ & $\begin{array}{l}\text { Polícia Rodoviária } \\
\text { Federal }-\mathrm{km} \mathrm{9}\end{array}$ \\
\hline P3 & $22640.00 \mathrm{~m} \mathrm{~N}$ & $487024.00 \mathrm{~m} \mathrm{E}$ & KM -21 \\
\hline P4 & $46782.09 \mathrm{~m} \mathrm{~N}$ & $494626.90 \mathrm{~m} \mathrm{E}$ & $\mathrm{KM}-50$ \\
\hline
\end{tabular}

Disponível em: https://www.nucleodoconhecimento.com.br/geografia/georreferenciamento-de- 


\begin{tabular}{|c|c|c|c|}
\hline P5 & $76122.34 \mathrm{~m} \mathrm{~N}$ & $459035.33 \mathrm{~m} \mathrm{E}$ & $\begin{array}{l}\text { Entrada de Porto } \\
\text { Grande }\end{array}$ \\
\hline P6 & $77974.18 \mathrm{~m} \mathrm{~N}$ & $454027.92 \mathrm{~m} \mathrm{E}$ & $\begin{array}{l}\text { Balneário de Porto } \\
\text { Grande }\end{array}$ \\
\hline P7 & $81092.93 \mathrm{~m} \mathrm{~N}$ & $461736.10 \mathrm{~m} \mathrm{E}$ & Estrada do Areal 1 \\
\hline P8 & $79286.46 \mathrm{~m} \mathrm{~N}$ & $463641.46 \mathrm{~m} \mathrm{E}$ & Estrada do Areal 2 \\
\hline P9 & $78505.50 \mathrm{~m} \mathrm{~N}$ & $462784.96 \mathrm{~m} \mathrm{E}$ & $\begin{array}{l}\text { Areal em Ferreira } \\
\text { Gomes }\end{array}$ \\
\hline
\end{tabular}

Figura 6. Descrição do trajeto do IFAP ao areal Morro Branco.



(EARTH, 2018). 
Figura 7. Descrição do trajeto, área do areal Morro Branco. km.

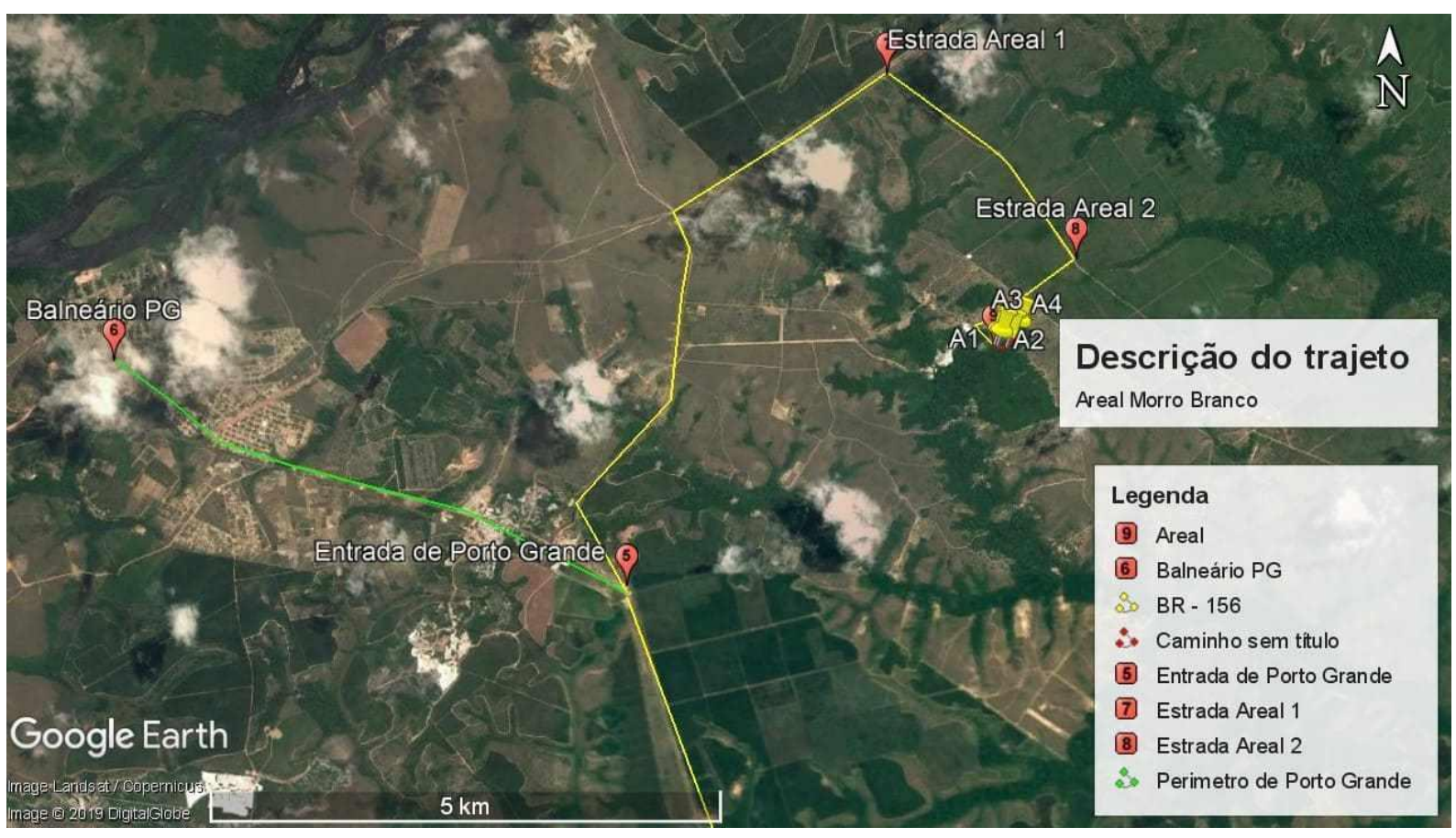

(EARTH, 2018).

Os principais pontos de coleta de amostras foram delimitados por latitude, longitude e descrição (Tabela 2 e Figura 8, 9).

Tabela 2. Descrição dos pontos de coleta de amostras, latitude, longitude e descrição.

\begin{tabular}{|c|c|c|c|}
\hline $\begin{array}{l}\text { Pontos de } \\
\text { coleta de } \\
\text { amostras }\end{array}$ & Latitude & Longitude & Descrição \\
\hline A01 & $78337.20 \mathrm{~m} \mathrm{~N}$ & $462795.45 \mathrm{~m} \mathrm{E}$ & \multirow{4}{*}{$\begin{array}{l}\text { Areal em Ferreira } \\
\text { Gomes }\end{array}$} \\
\hline A02 & $78325.41 \mathrm{~m} \mathrm{~N}$ & $462824.42 \mathrm{~m} \mathrm{E}$ & \\
\hline A03 & $78311.81 \mathrm{~m} \mathrm{~N}$ & $462813.73 \mathrm{~m} \mathrm{E}$ & \\
\hline A04 & $78424.34 \mathrm{~m} \mathrm{~N}$ & $463005.49 \mathrm{~m} \mathrm{E}$ & \\
\hline
\end{tabular}

Disponível em: https://www.nucleodoconhecimento.com.br/geografia/georreferenciamento-de- 
Figura 8. Descrição dos pontos da coleta de amostras. Altitude dos pontos de visão: $468 \mathrm{~m}$.

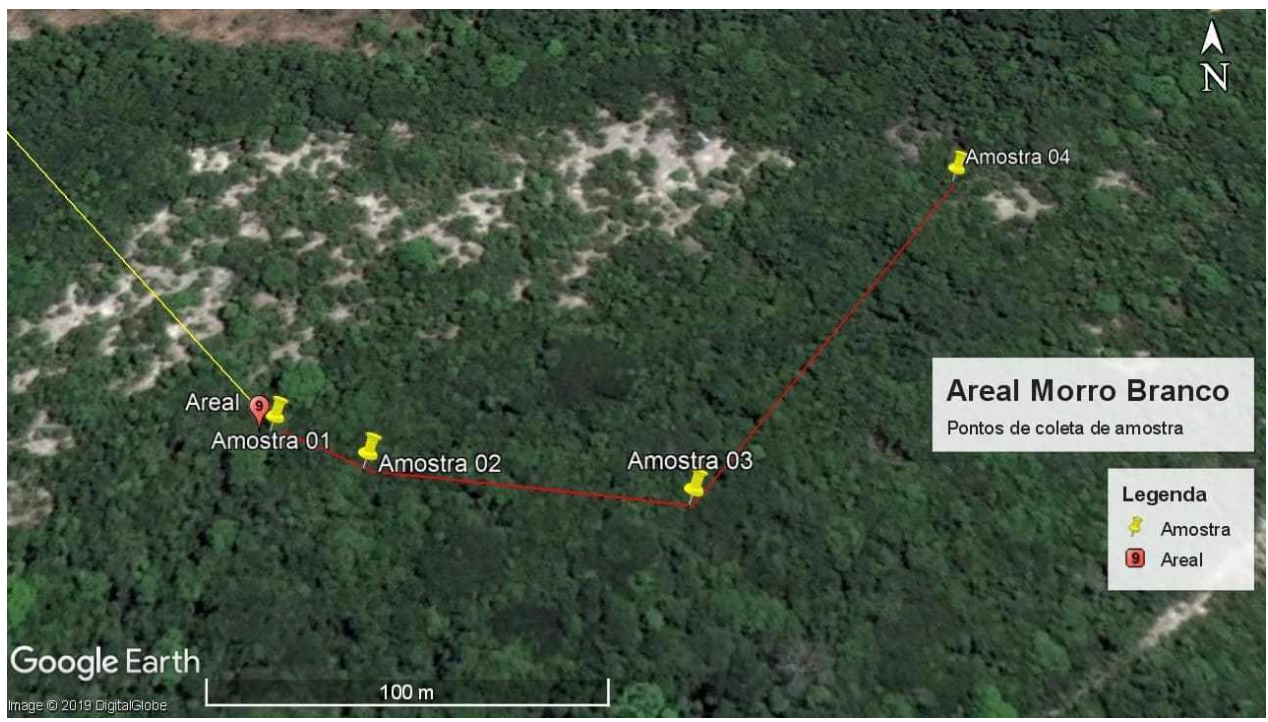

(EARTH, 2018).

Figura 9. Mapa de pontos na área de extração, apresentando o georreferenciamento executado pelos alunos participantes da equipe de trabalho de campo, onde pode se evidenciar o contorno exato da cava de exploração, mostrando bastante diferença da informação reproduzida pela imagem de satélite.

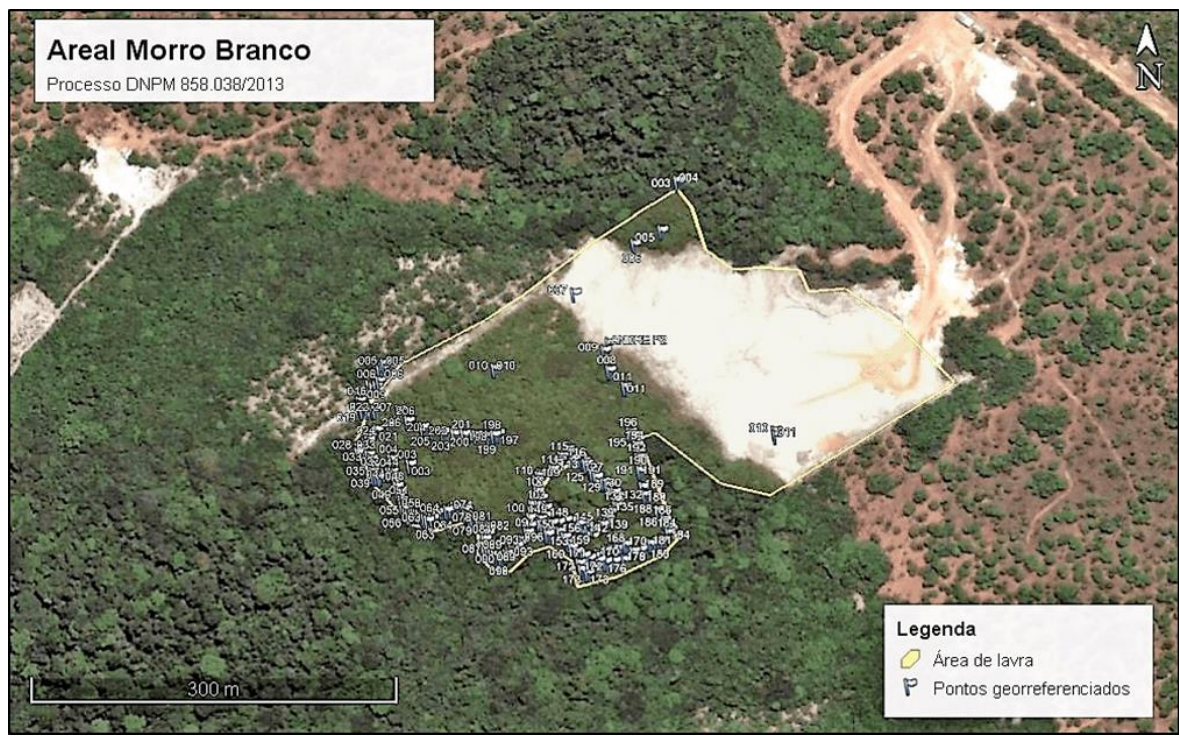

(EARTH, 2018).

RC: 42128

Disponível em: https://www.nucleodoconhecimento.com.br/geografia/georreferenciamento-deuma-area 
Todos os dados extraídos do receptor GPS foram compilados na ferramenta Google Earth onde se tornou possível analisar melhor os pontos coletados e com isso, definir, na atualidade, a dimensão real da área de exploração do areal Morro Branco (EARTH, 2018).

\section{RESULTADOS E DISCUSSÃO}

Foram marcados pontos em locais distintos da BR-156, que possibilitou a verificação do caminho, com a precisão dos instrumentos de georreferenciamento, desde a cidade de Macapá até o local de extração de areia, Areal Morro Branco, em Ferreira Gomes-AP. Estas informações serviram para compilar um mapa de localização.

Diversos outros pontos foram coletados no areal a fim de demarcar a área de exploração da areia. Estes resultados, possibilitaram a confecção de um mapa de contorno da cava de exploração de areia.

Os dados de precisão da localização e da área de exploração, contribuem sobre maneira com os demais estudos que foram executados no local, como: a geologia local, a topografia, as operações de lavra e os impactos ambientais.

\section{CONCLUSÃO}

A precisão dos instrumentos de georreferenciamento do sistema GPS, aplicados aos conhecimentos de geomática, possibilitaram o aprimoramento dos estudos de geologia em uma área extração de areia, Areal Morro Branco, em Ferreira GomesAP.

Estas informações serviram para compilar mapas com a espacialização geográfica do local e definir com exatidão a área de extração de areia.

$\mathrm{Na}$ execução do trabalho, a inovação tecnológica, pautada nas geotecnologias, propiciaram o aprimoramento das informações obtidas. 
Os dados coletados e analisados contribuíram com novas informações do contexto geológico do local. Também servirão para orientar o trabalho de extração de areia, de forma mais ordenada, por parte da empresa mineradora.

As técnicas de georreferenciamento aplicadas neste trabalho, possibilitaram o aprendizado dos alunos no trabalho de exploração geológica de campo.

\section{REFERÊNCIAS}

AMAPÁ. Histórico. Ferreira Gomes AP, 2017. Disponível em: $<$ http://www.ferreiragomes.ap.gov.br/conteudo/sobre-o-municipio/historico >. Acesso em: 15 Julho 2018.

CARVALHO, E. H.; ARAÚJO, P. C. Noções básicas de sistema de posicionamento global GPS. Natal RN: EDUFRN, 2009a. 244p.

CPRM. Banco de dados GeoSGB. 2017. Disponível em: < http://geosgb.cprm.gov.br >. Acesso em: 20 Julho 2018.

EARTH,

G. AP-010.

2018.

Disponível

em:

https://www.google.com.br/earth/download/gep/agree.html >. Acesso em: 12 junho 2018.

FERREIRA, R. S.; SANTOS, R. Mapeamento Temporal da Área Urbana do Município de Ferreira Gomes - AP por Imagens Landsat. I Congresso Nacional de Geografia Fisica. Campinas SP 2017.

GOMES, T. S. Fundamentos de GPS: Conceitos, Operação e Configuração. Brasília DF, 2010. Disponível em: <http://www.mda.gov.br/sitemda/sites/sitemda/files/user_arquivos_383/Apostila\%20d e\%20GPS\%20-\%20Curso\%20Sig@livre\%20Sist\%C3\%AAmico.pdf >. Acesso em: 20 Junho 2018. 
IBGE. Ferreira Gomes / Panorama. 2017. Disponível em: < https://cidades.ibge.gov.br/brasil/ap/ferreira-gomes/panorama >. Acesso em: 15 Julho 2018.

- Mapa Geológico do Estado do Amapá. 2019. Disponível em: < ftp://geoftp.ibge.gov.br/informacoes_ambientais/geologia/levantamento_geologico/m apas/unidades_da_federacao/ap_geologia.pdf >. Acesso em: 22 Agosto 2018.

MAGALHÃES, L. A.; SOUZA FILHO, C. R.; SILVA, A. M. Caracterização geológica geofísica da porção central do Amapá com base em processamento e interpretação de dados geofísicos. Revista Brasileira de Geociências, v. 37, n. 3, p. 464477, 2007.

MENZORI, M. Georreferenciamento: Conceitos. São Paulo SP: Baraúna, 2017.

MONICO, J. F. G. Posicionamento pelo NAVSTAR-GPS: Descrição, fundamentos e aplicações. São Paulo SP: UNESP, 2000. 287p.

OLIVEIRA, M. J. D. et al. Diagnóstico do setor mineral do Estado do Amapá. Macapá AP: IEPA, 2010. 148p.

PIMENTEL, M. M.; SPIER, C. A.; FERREIRA FILHO, C. F. Estudo Sm-Nd do complexo máfico-ultramáfico Bacuri, Amapá: idade da intrusão, metamorfismo e natureza do magma original. Revista Brasileira de Geociências, v. 32, n. 3, p. 371-376, 2002.

PIRES, J. et al. Sistema GPS. 2014. Disponível em: < https://paginas.fe.up.pt/ projfeup/submit_13_14/uploads/relat_1MIEEC03_2.pdf >. Acesso em: 28 Maio 2018.

RABELO, B. V. et al. Macrodiagnóstico do Estado do Amapá: primeira aproximação do ZEE. Macapá AP: IEPA, 2008. 140p.

ROQUE, C. G. et al. Georreferenciamento. Revista de Ciências Agro-Ambientais, v. 4, n. 1, p. 87-102, 2006. 
SANTOS, H., R. Comparação entre os métodos GPS e imagem de satélite em levantamentos de áreas florestais. 2012. 21p (Especialização). Universidade Federal do Paraná, Curitiba PR.

Enviado: Setembro, 2019.

Aprovado: Outubro, 2019. 